\title{
Analysis of national measles surveillance data in Italy from October 2010 to December 2011 and priorities for reaching the 2015 measles elimination goal
}

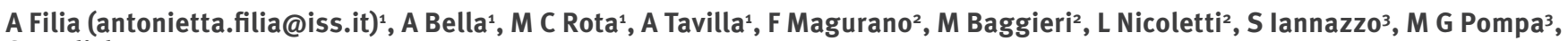
S Declich ${ }^{1}$

1. Infectious Diseases Epidemiology Unit, National Institute of Health, Rome, Italy

2. Viral Diseases and Attenuated Vaccines Unit, National Institute of Health, Rome, Italy

3. Infectious Diseases and International Prophylaxis Office, Ministry of Health, Rome, Italy

Citation style for this article:

Filia A, Bella A, Rota MC, Tavilla A, Magurano F, Baggieri M, Nicoletti L, Iannazzo S, Pompa MG, Declich S. Analysis of national measles surveillance data in Italy from October 2010 to December 2011 and priorities for reaching the 2015 measles elimination goal . Euro Surveill. 2013;18(20):pii=20480. Available online: http:// www.eurosurveillance.org/ViewArticle.aspx?Articleld $=20480$

Article submitted on 30 July 2012 / published on 16 May 2013

From 1 October 2010 to 31 December 2011, Italy experienced high measles burden with 5,568 measles cases ( $37.4 \%$ laboratory-confirmed) reported to the enhanced measles surveillance system (cumulative incidence in the 15 -month reference period: $9.2 / 100,000$ population). Adolescents and young adults were especially affected, and the median age of cases was 18 years. Most cases $(95.8 \%)$ were either unvaccinated or incompletely vaccinated. Complications were reported for $\mathbf{2 0 . 3 \%}$ of cases, including 135 cases of pneumonia, seven of encephalitis and one case of Guillain-Barré syndrome. One death occurred in an immunocompromised adult. Over 1,300 cases were hospitalised. Identified priorities for reaching the measles elimination goal include evidence-based interventions such as reminder/recall for both doses of measles vaccine, supplementary immunisation activities aimed at susceptible age cohorts, and vaccinating healthcare workers.

\section{Introduction}

Measles is an acute viral illness with the potential for severe and life-threatening complications. The disease can be prevented by a safe and effective vaccine and globally, measles control activities have been very successful in reducing measles incidence and mortality. Since measles virus infects only humans, elimination is possible, and all regions of the World Health Organization (WHO) except the South-East Asia Region have set an elimination goal to be achieved by 2020 or sooner $[1,2]$. In the European Region the target date for elimination has recently been moved from 2010 to 2015. As most other European countries, Italy failed to reach measles elimination by 2010 and in accordance with European goals, also revised its target date for elimination to 2015 [3]. Thanks to intensive vaccination and surveillance efforts, elimination was achieved in the WHO Region of the Americas in 2002 and in many other countries such as Finland (in 1994) and South Korea (in 2006) [1, 4-5].
The very high transmissibility of measles infection, as evidenced by a basic reproduction number (Ro) between 11 and18, poses a great challenge to elimination and requires very low susceptibility levels in the population [6]. This can be achieved by reaching and maintaining very high coverage levels of over $95 \%$ for two doses of measles vaccine. Besides introducing a routine two-dose schedule for measles vaccine, most countries that have interrupted endemic measles transmission have also undertaken supplementary mass immunisation activities (SIAs) to rapidly immunise a high proportion of susceptible persons in the population $[5,7-8]$.

Measles vaccination strategy and uptake in Italy In Italy, monovalent measles vaccine was first introduced in 1976. This was replaced in the early 1990 s by the combined measles-mumps-rubella (MMR) vaccine, but only since 1999 has vaccination with MMR been included in the national immunisation programme. Only one dose of MMR was offered until 2003 when Italy approved the first national measles elimination plan and a two-dose schedule was adopted in all regions starting with the 2002 birth cohort [9]. Currently, a first dose of MMR vaccine is recommended at the age of 12 to15 months and a second dose at five to six years.

The Italian national health system is decentralised, but state authorities determine the minimum level of healthcare services that regional authorities must provide to citizens free of charge. With regards to vaccination, the National Vaccine Plan outlines the objectives of the national immunisation programme, agreed upon by regional authorities who are responsible for the implementation of vaccination programmes in their respective regions [10]. In all regions, vaccinations included in the national immunisation programme (including MMR) must be provided free of charge by local vaccination 


\section{FIGURE 1}

Vaccine coverage for the first dose of measles-containing vaccine in children aged two years (administrative method), by region. Italy, 2011

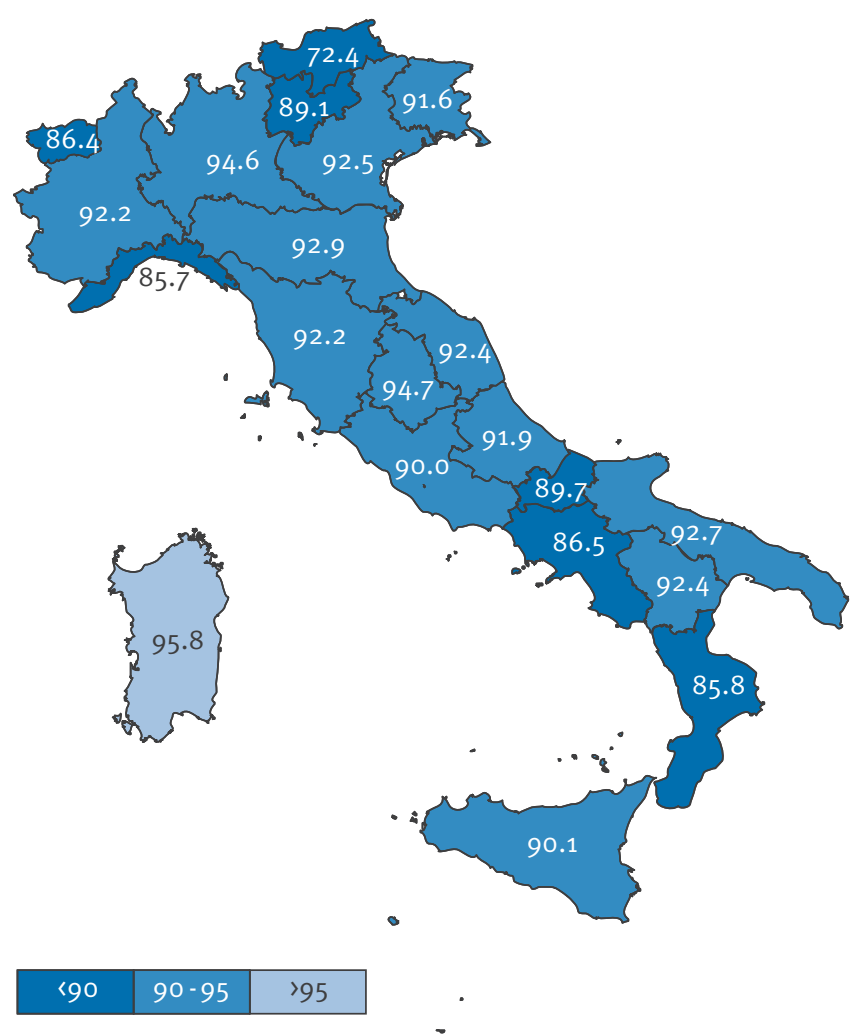

centres. Family paediatricians and general practitioners generally do not provide vaccinations.

Vaccination coverage for all childhood vaccines included in the national immunisation schedule is measured annually in two year-old children in all regions, by the administrative method (dividing the number of vaccine doses administered in the target population by the number of persons in the target population). In addition, epi-cluster surveys were conducted in 1998, 2003 and 2008, to validate administrative coverage data and to collect information regarding reasons for non-vaccination [11]. The 2008 epi-cluster survey also aimed at collecting information on vaccination coverage in 16 year-old adolescents (1992 birth cohort), including data on second-dose MMR coverage which is not routinely measured in Italy.

Uptake of measles vaccine remained very low in Italy for years after its introduction and was not uniform across regions. The percentage of two year-old children vaccinated against measles was consistently below $21 \%$ before 1988 , increased to $50 \%$ in the 1990 , reaching $74 \%$ in the year 2000 . Since the implementation of the first national measles elimination plan in 2003 , coverage with measles-containing vaccine increased to $90.1 \%$ in 2011 (Figure 1) [12]. According to the 2008 epi-cluster survey, conducted in 18 of 21 Italian regions, measles vaccine coverage in 16 yearold adolescents was $78.1 \%$ for the first dose and only $53.9 \%$ for the second dose [11].

A supplementary catch-up immunisation campaign was conducted in the years 2003 to 2005 , targeting 2,544,386 children born in the years 1991 to 1997 . Overall MMR vaccination coverage in this group, measured at the start of the campaign, was $71 \%$ for the first dose and only $15 \%$ for the second dose. Following the campaign, first-dose coverage increased to $81 \%$ and second-dose coverage to $39 \%$.

\section{Measles incidence}

The Italian measles surveillance system has been previously described [13]. The overall incidence of measles has decreased in Italy since the measles vaccine was introduced, from a mean incidence of 150 cases per 100,000 population in the 1970 s to 81 cases per 100,000 in the 1980 s and 41 cases per 100,000 in the 9os. In the past decade, large epidemics occurred in the years 2002 to 2003 and in 2008, with 18,020 reported cases (incidence $32 / 100,000$ population) in 2002 and 5,312 cases in 2008 (8.9/100,000 population). The latter outbreak affected mainly northern Italian regions, especially the Piedmont region (46\% of cases). A new resurgence of cases was then observed in December 2009 [13]. Outbreaks in recent years have mainly affected adolescents and young adults [13-14].

In this article we describe measles cases reported to the Italian national measles surveillance system with dates of rash onset between 1 October 2010 and 31 December 2011, and discuss some of the priorities for reaching measles elimination. Since measles is targeted for elimination in the European Region, it is worthwhile to share information with other public health actors in Europe and direct attention to the severity of measles even in industrialised countries.

\section{Methods}

Reported cases were classified according to the 2008 European Commission (EC) case definition for measles [15]. Recent vaccination was defined as having received a measles-containing vaccine six to 45 days before onset of rash [16]. Recently vaccinated cases with a positive IgM response were classified as possible or probable cases according to clinical and epidemiological criteria. Suspected cases not meeting the EC measles case definition were discarded. Cases vaccinated up to and including four days before rash onset were probably incubating the disease at the time of vaccination and were classified either as not vaccinated (if they had received only one dose) or as vaccinated with one dose (if the recent vaccination was the second dose). Imported cases were defined as cases exposed outside the country during a period seven to18 days before rash onset as supported by epidemiological and/or virological evidence [17]. Healthcare worker was defined as any hospital staff or other healthcare staff 
having regular contact with patients, including clinical physicians, nurses, students in these disciplines, paramedical professionals, social workers, ambulance workers, porters, other hospital support staff, and healthcare staff in primary care medical facilities and nursing homes.

Incidence was calculated by using age-specific population data for 2011, by region and geographical area, obtained from the National Institute of Statistics (Istituto Nazionale di Statistica, ISTAT) [18]. Three geographical areas are described in Italy: northern, central and southern Italy. Northern Italy includes the following nine regions: Piedmont, Valle d'Aosta, Liguria, Lombardy, South Tyrol, Autonomous Province of Trento, Veneto, Friuli-Venezia Giulia, and EmiliaRomagna. Central Italy includes Marche, Tuscany, Umbria and Lazio. Southern regions include Campania, Abruzzo, Molise, Apulia, Basilicata, Calabria, Sicily and Sardinia.

Biological samples for genotyping were analysed by the national reference laboratory at the National Institute of Health in Rome. Data were analysed using Excel and Epi Info software.

\section{Results}

A total of 5,568 possible, probable or confirmed cases were reported, giving a national cumulative incidence in the 15 -month reference period of 9.2 per 100,000 population (population of 60,626,442 as of 1 Jan 2011). An additional 1,103 suspected cases were reported and discarded because they did not meet the measles case definition for a possible, probable or confirmed case. Overall, 2,085 cases (37.4\%) were laboratoryconfirmed, 1,902 (34.2\%) were probable cases and $1,581(28.4 \%)$ were possible cases. The epidemic curve (Figure 2) shows that the peak number of reported cases was reached in May $2011(n=1,195)$.

Twenty of 21 regions and autonomous provinces (AP) reported cases, with incidences varying from 0.2 per 100,000 population to 246.6 per 100,000 population (Figure 3). The highest incidence rates were reported from two very small regions in northern Italy which accounted for $31.8 \%$ of cases $(n=1,772)$ : South Tyrol (population 507,657; incidence 246.6/100,000) and the neighbouring AP of Trento (population 529,457; incidence 98.2/100,000). The Lazio region, in central Italy, also reported a high incidence (population 5,728,688; incidence $27.5 / 100,000$ ). Two regions in northern

\section{FIGURE 2}

Epidemic curve showing reported measles cases by month of rash onset and case classification, Italy, October 2010December $2011(n=5,568)$

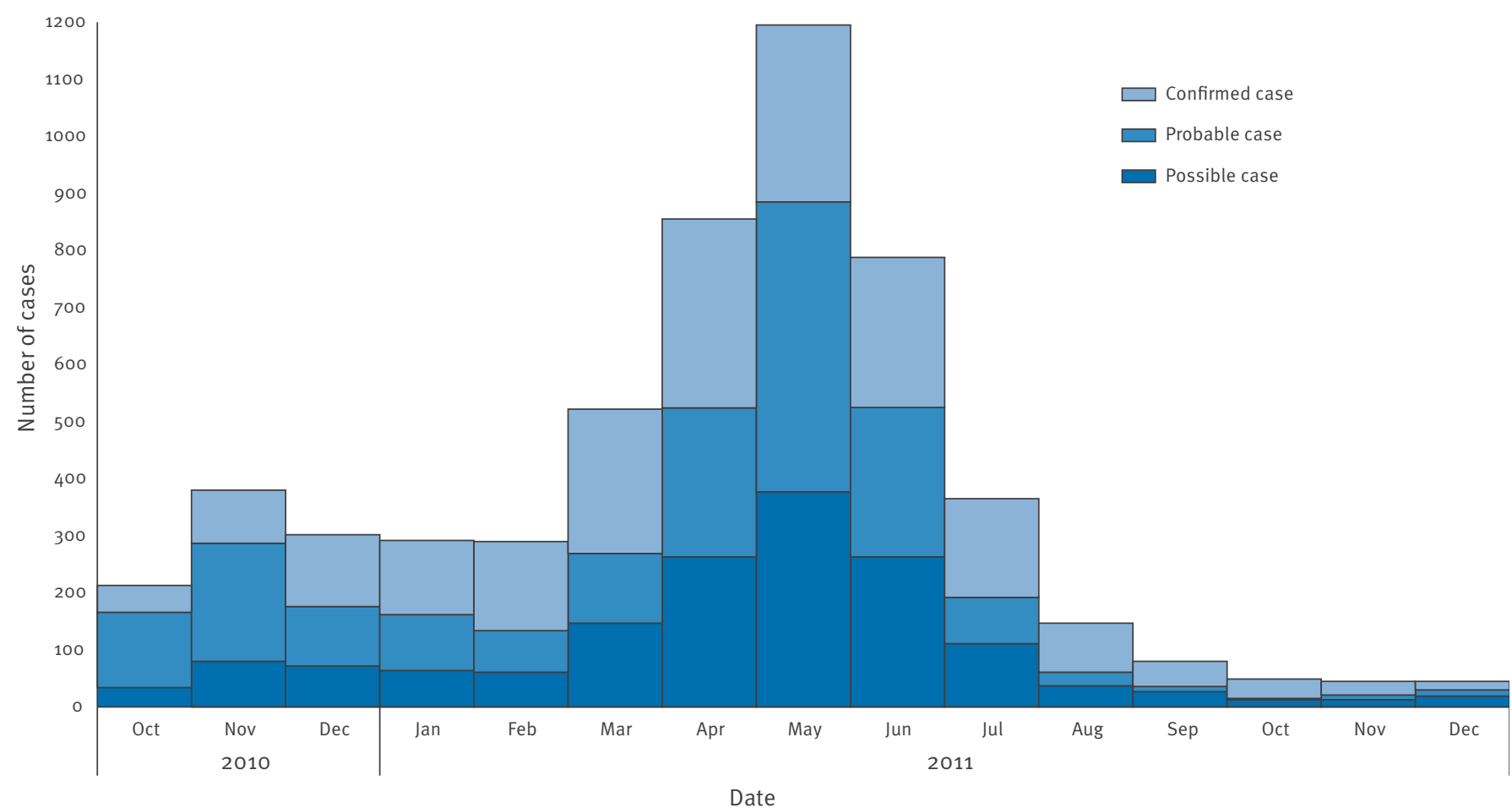




\section{FIGURE 3}

Reported measles incidence per 100,000 population, by region, Italy, October 2010- December $2011 \quad(n=5,568)$

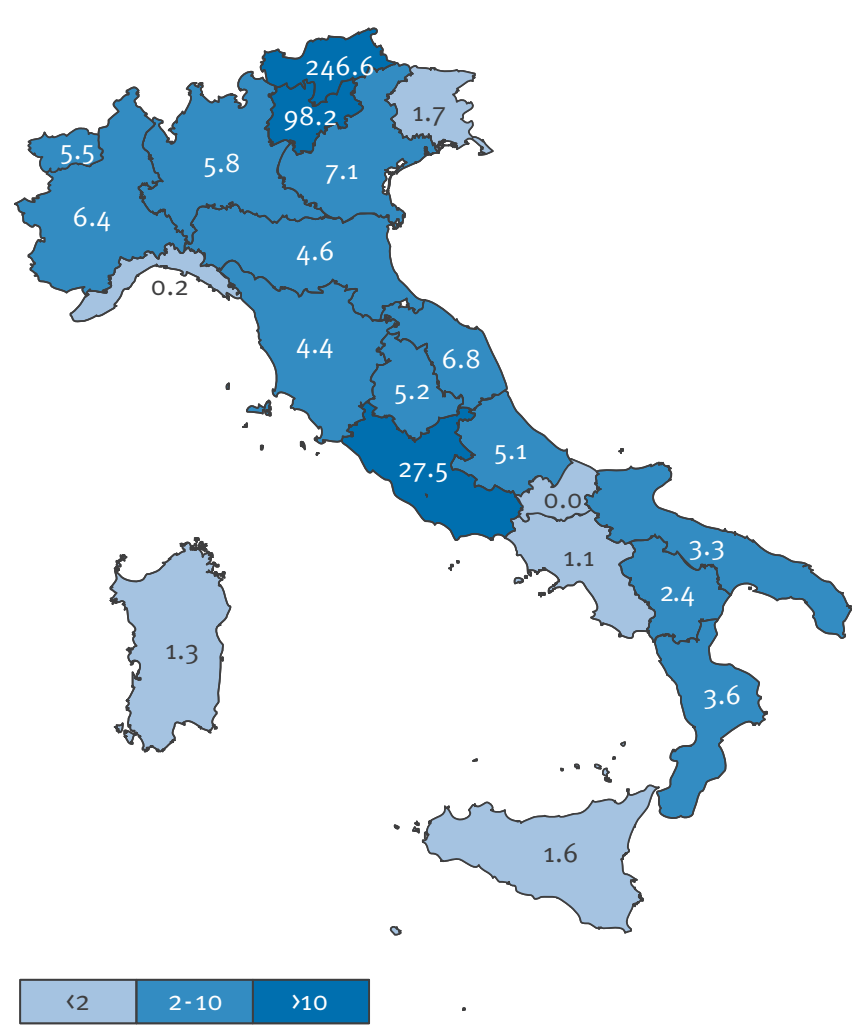

Italy (Valle d'Aosta and Liguria) reported less than 10 cases each. Incidences by geographical area were $11.6 / 100,000$ in northern Italy, 15.8/100,000 in central Italy, 2.2/100,000 in southern Italy.

\section{Age and sex of cases}

Information on sex was available for 5,565 cases (99.9\%): 2,955 (53.1\%) were male. Age was reported for 5,345 cases $(96.0 \%)$. The age distribution and incidence per age group are shown in Table 1.

The highest incidence was seen in the age group 15-19 years followed by the age group under one year. Sixty-two per cent of cases were aged 15-44 years. The median age was 18 years (range: two months -78 years) and varied by region from four years in the Valle d'Aosta region (northern Italy), where only seven cases were reported, to 28.5 years in the Marche region in central Italy $(n=107)$. In 13 regions the median age of reported cases was above the national figure (range: 21-28.5 years).

\section{Vaccination status}

Vaccination status was available for 4,938 cases (88.7\%). Overall, 4,458 cases (90.3\%) were unvaccinated, $272(5.5 \%)$ had received only one dose of measles-containing vaccine, $36(0.7 \%)$ were vaccinated with two doses, and 172 cases (3.5\%) had received at least one dose but the number of doses was unspecified. Among unvaccinated cases, 164 were too young to be vaccinated routinely (aged under one year).

\section{Complications and hospitalisations}

Overall, 1,130 cases $(20.3 \%)$ reported at least one complication, and a total of 1,544 complications were reported (Table 2). The median age of complicated cases was 19 years (range: 0-68 years) and the highest frequency of complications (28.6\%) was seen in the age group 25-44 years. Information regarding hospital admissions for measles was available for 5,034 patients (90.4\%), of whom 1,317 (26.2\%) were hospitalised.

Diarrhoea was the most frequently reported complication but more severe complications such as pneumonia, thrombocytopenia, and encephalitis were also reported. The category 'Other complications' included respiratory complications, vomiting and dehydration, hepatitis, arthralgias, and complications in pregnancy. A case of Guillain-Barré syndrome was also reported. Three cases developed respiratory failure.

The seven reported cases of encephalitis ranged in age from 13 to 62 years (median: 29 years). Five of seven cases were laboratory-confirmed, one had an epidemiological link to a confirmed case and one was a clinical case. None had been vaccinated against measles. One case of encephalitis occurred in a healthcare worker (HCW).

A young adult patient who developed measles in late 2011, subsequently died 64 days after rash onset. The patient was affected by hypogammaglobulinaemia and developed laboratory-confirmed measles following contact with an infected co-worker. The cause of death was pneumonia with respiratory failure.

\section{TABLE 1}

Age distribution of measles cases and incidence by age group, Italy, October 2010-December $2011\left(\mathrm{n}=5,345^{\mathrm{a}}\right)$

\begin{tabular}{|l|c|c|}
\hline Age group (years) & Number of cases & $\begin{array}{c}\text { Incidence per 100,000 } \\
\text { population }\end{array}$ \\
\hline$<1$ & 181 & 32.6 \\
\hline $1-4$ & 450 & 19.6 \\
\hline $5-9$ & 452 & 15.9 \\
\hline $10-14$ & 812 & 28.7 \\
\hline $15-19$ & 1,130 & 38.5 \\
\hline $20-24$ & 773 & 24.7 \\
\hline $25-44$ & 1,387 & 8.0 \\
\hline$\geq 45$ & 160 & 0.6 \\
\hline
\end{tabular}

${ }^{a}$ Information on age was not available for 223 of 5,568 cases. 
TABLE 2

Reported measles complications, Italy, October 2010December 2011

\begin{tabular}{|l|c|c|}
\hline Diagnosis & $\begin{array}{c}\text { Number of } \\
\text { reports }\end{array}$ & $\begin{array}{c}\text { Incidence per 1,000 } \\
\text { measles cases }\end{array}$ \\
\hline Diarrhoea & 634 & 113.9 \\
\hline Otitis & 195 & 35.0 \\
\hline Pneumonia & 135 & 24.2 \\
\hline Keratoconjunctivitis & 104 & 18.7 \\
\hline Laryngotracheobronchitis & 167 & 30.0 \\
\hline Thrombocytopenia & 9 & 1.6 \\
\hline Encephalitis & 7 & 1.3 \\
\hline Convulsions & 10 & 1.8 \\
\hline Other complication & 283 & 50.8 \\
\hline Total & 1,544 & 27.7 \\
\hline
\end{tabular}

a Calculated using as the denominator the total number of measles cases reported, $n=5,568$.

b A total of 1,130 cases reported at least one complication; some reported more than one complication.

Transmission settings and occupation of cases Transmission occurred in various settings including families, schools (nursery schools, elementary and middle schools, universities), healthcare facilities, vacation camps and other community settings. Healthcare settings in which transmission occurred included hospital wards and emergency rooms.

Since the type of occupation cannot be reported for students and pre-school children, this information is available only for 1,595 cases $(28.6 \%), 185$ of whom were HCWs. Some 164 of 185 (88.7\%) HCWs were unvaccinated, $14(7.6 \%)$ were not aware of their measles vaccination status, five $(2.7 \%)$ had received one dose of measles vaccine, one (0.5\%) had received two doses, and one ( $0.5 \%)$ had been vaccinated but could not recall the number of doses received. Forty-four cases with known occupation were school workers, of whom 38 were unvaccinated, five were not aware of their measles vaccination status, and one had received two doses.

Four regions in northern Italy (Lombardy, Friuli Venezia Giulia, AP Trento and Emilia Romagna) reported measles cases among Roma/Sinti populations, for a total of 40 cases: in Lombardy, 10 clusters were reported for a total of 28 cases; Emilia Romagna reported nine cases, eight of whom were part of a single cluster; Friuli Venezia Giulia and AP Trento reported one and two cases, respectively.

A total of 32 cases were likely to have acquired measles abroad, mainly from other European countries such as France, Germany and the United Kingdom, but four cases were imported from North Africa, India, and China.

\section{Phylogenetic analysis of measles virus}

Measles viruses, from specimens collected from 257 cases in 15 of the 20 affected regions, were genotyped and three main genotypes were detected: D4 (isolated from 161 cases in 14 regions), D8 (isolated from 69 cases in 11 regions), and $B_{3}$ (23 cases in eight regions). Genotypes D9 (two cases in one region), $\mathrm{H}_{1}$ (single case) and A genotypes (single case) were isolated from the remaining four specimens.

\section{Discussion}

From October 2010 and throughout 2011, Italy experienced a severe measles burden with a cumulative incidence that was 2.5 times higher than that reported in the previous 15-month period [13]. Factors contributing to this upsurge include suboptimal routine vaccination coverage ( $(95 \%)$ and especially the presence of large numbers of susceptible adolescents and young adults born in the 1980 s and 1990 s when uptake of measles vaccine was very low and the second dose had not yet been introduced. Adolescents and young adults have been frequently affected in outbreaks in recent years, but there continue to be high levels of susceptibility in these age groups.

Incidence varied greatly among geographical regions, and factors such as local epidemiology and accumulation of susceptible groups, but also underreporting, may account for these differences. The degree of underreporting to the enhanced measles surveillance system is unknown. However, a study performed in the year 2000 indicated that the national measles incidence in Italy, as estimated through data from a network of sentinel paediatricians that existed at the time, was 3.6 times higher than that estimated from statutory notification data [19]. Underreporting was found to be significantly higher in southern Italy than in northern and central Italy: the ratio between measles incidence estimated through the sentinel system and that estimated through statutory notification data was 1:1 in northern Italy, 3:1 in central Italy and 22:1 in southern Italy. Although patterns of measles reporting may since have changed, our data seem to indicate a continuing greater degree of underreporting in southern Italy.

The frequency of complications is within the range of frequencies reported in other European countries $(11.4-38.6 \%)$ [20-24]. The wide range of frequencies reported in the literature may be partly due to different degrees of underreporting in the various settings but also to differences in the types of complications being reported and in different age distributions of cases. Measles complications can affect almost any organ system, but the types included in published studies 
are not always specified and may differ from one setting to the next.

One measles-related death occurred in an immunocompromised patient in 2012 and was reported here because the patient had developed measles rash during the study period. Death occurred 64 days after rash onset and was due to respiratory complications of measles. The WHO defines a measles-associated death as one occurring within 30 days of rash onset and not obviously due to another cause. However, a broad range of death definitions are used in case fatality studies [25]. This death serves as a reminder that immunocompromised persons are at particular risk of severe measles complications and depend on high vaccination coverage among their contacts to protect them from infection.

In 2011, Italy renewed its commitment to eliminate measles by approving a new national elimination plan [3]. The plan, which addresses once again all components of the WHO elimination strategy, was approved by the State-Regions collegial body (Conferenza Stato Regioni), which means that all 21 regions have committed to the objectives and strategies included in the plan. Following approval of the elimination plan, a national task force of representatives of the Ministry of Health, the National Health Institute and five regional health authorities, has been established to define priorities, coordinate activities, prepare technical documents, promote sharing of information and best practice between the different regions, and implement elimination strategies in all regions. A monitoring and evaluation framework has been developed based on the recently published document by the WHO Regional Office for Europe [17].

One of the priorities identified by the task force is to improve the delivery of MMR vaccine by implementing a standard protocol for systematic reminder/recall interventions by telephone or post, to be adopted in all local health authorities for both doses of MMR vaccine. Reminder/recall is an evidence-based strategy that has been shown to be effective in increasing vaccination uptake in young children and adults, and a recent study has shown its effectiveness in adolescents as well [2627]. A survey conducted in Italy in 2009 to evaluate the degree of implementation of strategies included in the first national measles elimination plan revealed that reminder/recall activities for the first dose of MMR vaccine at 12-15 months of age were being conducted in $93 \%$ of 143 local health authorities while $90 \%$ conducted reminder/recall for the second MMR dose at five to six years [28]. However, the types and combinations of reminder/recall activities used in the various vaccination centres may vary, and there are no data documenting whether the implemented interventions have successfully increased MMR coverage rates locally.

A second priority identified by the task force is conducting a national MMR catch-up campaign. A mathematical modelling study is being conducted to identify the age cohorts to be targeted in each region. The model will take into consideration historical and current MMR coverage levels, case notifications and the median age of reported cases in the each region.

Additional immunisation efforts should be targeted at susceptible groups such as HCWs who accounted for a non-negligible proportion (11.6\%) of cases for whom the information on occupation was recorded. It is well known that HCWs are at higher risk of exposure to measles than the general population and a HCW with measles will inevitably result in large numbers of exposed high-risk patients [29]. In Italy, measles vaccination is recommended for all susceptible HCWs [30] and individual regions have developed specific guidelines; however, documentation of measles immunity is not required for employment as a doctor or nurse or for medical or nursing students in training and no coverage data among HCWs is available. Seroprevalence studies performed in HCWs in Italy indicate varying levels of seropositivity but always higher than 90\% [31]. A study conducted in France showed that knowledge of recommended occupational vaccinations is insufficient in HCWs [32]. Italian HCWs' attitudes towards measles vaccination and barriers to immunisation should be investigated.

\section{Conclusion}

The experience of 2011 demonstrates that there are still major challenges to the country's 2015 elimination goals in Italy, as in the rest of Europe. In Italy, several priorities have been identified by the national task force, but all regions need to be fully committed to eliminating measles by taking action to reach high population immunity in children, identify susceptible groups and conduct supplementary immunisation activities.

\section{Acknowledgements}

The authors wish to thank all regional and local health authorities for their work in measles surveillance and outbreak control activities. We also thank Claudia Fortuna, Antonella Marchi, Paola Bucci and Eleonora Benedetti for their work at the national measles reference laboratory (National Institute of Health).

\section{References}

1. Mulholland EK, Griffiths UK, Biellik R. Measles in the 21st century. N Engl J Med. 2012; 366(19):1755-7. http://dx.doi.org/10.1056/NEJMp1202396 PMid:22571199

2. Moss WJ, Griffin DE. Measles. Lancet. 2012;379(9811):153-64. http://dx.doi.org/10.1016/S0140-6736(10)62352-5

3. Italian Ministry of Health. Piano nazionale per l'eliminazione del morbillo e della rosolia congenita 2010-2015. [National Plan for the elimination of measles and congenital rubella 2010-2015]. Rome: Ministero della Salute; 2011. Italian. Available from: http://www.salute.gov.it/imgs/C_17_ pubblicazioni_1519_allegato.pdf

4. Rose A. Measles eliminated in Finland since 1996 - will it last? Euro Surveill 2003;7(3): pii=2150. Available from: http://www. eurosurveillance.org/ViewArticle.aspx?Articleld $=2150$ 
5. Centers for Disease Control and Prevention (CDC). Elimination of Measles - South Korea, 2001-2006. MMWR Morb Mortal Wkly Rep. 2007;56(13);304-7. PMid:17410083

6. Gay N. The theory of measles elimination: implications for the design of elimination strategies. J Infect Dis. 2004;189(Suppl 1):S27-S35. http://dx.doi.org/10.1086/381592 PMid:15106086

7. Duke T, Mgone CS. Measles: not just another viral exanthema. Lancet. 2003;361(9359):763-73. http://dx.doi.org/10.1016/S0140-6736(03)12661-X

8. de Quadros CA, Hersh BS, Nogueira AC, Carrasco PA, da Silveira CM. Measles Eradication: Experience in the Americas. Bull World Health Organ. 1998;76 Suppl 2:47-52. PMid:10063674 PMCid:2305693

9. Italian Ministry of Health. Piano nazionale per l'eliminazione del morbillo e della rosolia congenita 2003-2007. [National Plan for the elimination of measles and congenital rubella 2003-2007]. Rome: Ministero della Salute; 2003. Italian. Available from: http://www.governo.it/backoffice/ allegati/20894-1712.pdf

10. Italian Ministry of Health. Piano nazionale prevenzione vaccinale 2012-2014. [National Vaccination Prevention Plan 2012-2014. Gazzetta Ufficiale [Official Bulletin]. 12 Mar 2012;no. 6o. Italian. Available from: http://www.salute.gov.it/ imgs/C 17_pubblicazioni_1721_allegato.pdf

11. ICONA Working Group. ICONA 2008: Indagine di copertura vaccinale nazionale nei bambini e negli adolescenti. [ICONA 2008: national vaccination coverage survey among children and adolescents]. Rapporti Istisan 09/29. Rome: Istituto Superiore di Sanità; 2009. Italian. Available from: http://www. iss.it/binary/publ/cont/o9_29_web.pdf

12. Italian Ministry of Health. Malattie infettive e vaccinazioni. Coperture vaccinali. [Infectious diseases and vaccinations. Vaccine coverage.]. Rome: Ministero della Salute. [Accessed 13 May 2013]. Italian. Available from: http://www.salute.gov.it/ malattielnfettive/paginalnternaMenuMalattielnfettive.jsp?id=8 $11 \&$ menu=strumentieservizi

13. Filia A, Tavilla A, Bella A, Magurano F, Ansaldi F, Chironna M, et al. Measles in Italy, July 2009 to September 2010. Euro Surveill 2011;16(29):pii=19925. Available from: http://www. eurosurveillance.org/ViewArticle.aspx?Articleld =19925 PMid:21801692

14. Filia A, De Crescenzo M, Seyler T, Bella A, Ciofi Degli Atti ML, Nicoletti L,et al. Measles resurges in Italy: preliminary data from September 2007 to May 2008. Euro Surveill. 2008;13(29):pii=18928. Available from: http://www. eurosurveillance.org/viewarticle. aspx?articleid $=18928$ PMid:18761924

15. European Commission. Commission Decision of 28 April 2008 (2008/426/EC) amending Decision 2002/253/EC laying down case definitions for reporting communicable diseases to the Community network under Decision No 2119/98/EC of the European Parliament and of the Council. Official Journal of the European Union 18/6/2008; L159/46. Available from: http:// eur-lex.europa.eu/LexUriServ/LexUriServ.do?uri=0J:L:2008:15 9:0046:0090:EN:PDF

16. Roush S, Beall B, Cassiday P, Clayton H, Cushing K, Gentsch J, et al. Chapter 22: Laboratory support for the surveillance of vaccine-preventable diseases. In: VPD surveillance manual 5 th ed. Atlanta: Centers for Disease Control and Prevention; 2008. Available from: http://www.cdc.gov/vaccines/pubs/survmanual/chpt22-lab-support.pdf

17. World Health Organization Regional Office for Europe (WHO/ Europe). Eliminating measles and rubella. Framework for the verification process in the WHO European Region. Copenhagen: WHO/Europe; 2012. Available from: http://www.euro.who. int/_data/assets/pdf_file/0005/156776/eg6153-Eng-finalversion.pdf

18. Italian National Institute of Statistics (ISTAT). Precensal series of the resident population in the municipalities (2002-2011). Rome: ISTAT. [Accessed 13 May 2013]. Available from: http:// demo.istat.it/archive.html

19. Ciofi degli Atti ML, Salmaso S, Bella A, Arigliani R, Gangemi $M$, Chiamenti G, et al Pediatric sentinel surveillance of vaccine-preventable diseases in Italy. Pediatr Infect Dis J. 2002;21(8):763-8. http://dx.doi.org/10.1097/00006454200208000-00013 PMid:12192166

20. Huoi C, Casalegno JS, Bénet T, Neuraz A, Billaud G, Eibach $\mathrm{D}$, et al. A report on the large measles outbreak in Lyon, France, 2010 to 2011. Euro Surveill. 2012;17(36): pii=20264. Available from: http://www.eurosurveillance.org/ViewArticle. aspx?Articleld $=20264$ PMid:22971330

21. Delaporte E, Jeannot E, Sudre P, Wyler Lazarevic CA, Richard JL, Chastonay P. Measles in Geneva between 2003 and 2010: persistence of measles outbreaks despite high immunisation coverage. Euro Surveill 2011;16(39):pii=19980.
Available from: http://www.eurosurveillance.org/ViewArticle. aspx?Articleld $=19980$

22. Doshi S, Khetsuriani N, Zakhashvili K, Baidoshvili L, Imnadze P, Uzicanin A. Ongoing measles and rubella transmission on Georgia, 2004-05: implications for the national and regional elimination efforts. Int J Epidemiol. 2009;38(1):182-91. http://dx.doi.org/10.1093/ije/dyn261 PMid:19074954

23. Wichmann O, Siedler A, Sagebiel D, Hellenbrand W, Santibanez $S$, Mankertz A, et al. Further efforts needed to achieve measles elimination in Germany: results of an outbreak investigation. Bull World Health Organ. 2009;87(2):108-15.

http://dx.doi.org/10.2471/BLT.07.050187 PMid:19274362 PMCid:2636188

24. Stanescu A, Janta D, Lupulescu E, Necula G, Lazar M, Molnar $\mathrm{G}$, et al. Ongoing measles outbreak in Romania, 2011. Euro Surveill. 2011;16(31):pii=19932. Available from: http://www. eurosurveillance.org/ViewArticle.aspx?Articleld =19932 PMid:21871218

25. Wolfson LJ, Grais RF, Luquero FJ, Birmingham ME, Strebel PM. Estimates of measles case fatality ratios: a comprehensive review of community-based studies. Int J Epidemiol. 2009;38(1):192-205. http://dx.doi.org/10.1093/ije/dyn224 PMid:19188207

26. Suh CA, Saville A, Daley MF, Glazner JE, Barrow J, Stokley S, et al. Effectiveness and net cost of reminder/recall for adolescent immunizations. Pediatrics. 2012;129(6):e1437-45. http:// dx.doi.org/10.1542/peds.2011-1714 PMid:22566415

27. Task Force on Community Preventive Services. Chapter 6: Vaccine preventable diseases. In: Zaza S, Briss PA, Harris KW, editors. The guide to community preventive services. What works to promote health? New York: Oxford University Press; 2005. Available from: http://www.thecommunityguide.org/ library/book/index.html

28. Filia A, Rota MC, Del Manso M, D’Ancona P, Giambi C, Ranghiasci A, et al. Piano nazionale di eliminazione del morbillo e della rosolia congenita: indagine sullo stato di avanzamento (2009). [A survey to evaluate progress in implementation of the Italian measles and congenital rubella elimination plan (2009)]. Rapporti Istisan 10/45. Rome: Istituto Superiore di Sanità; 2010. Italian. Available from: http://www. iss.it/binary/publ/cont/10_45_web.pdf

29. Botelho-Nevers E, Gautret P, Biellik R, Brouqui P. Nosocomial transmission of measles: an updated review. Vaccine. 2012;30(27):3996-4001. http://dx.doi.org/10.1016/j. vaccine.2012.04.023 PMid:22521843

30. Maltezou HC, Wicker S, Borg M, Heininger U, Puro V, Theodoridou M, et al. Vaccination policies for health care workers in acute health-care facilities in Europe. Vaccine. 2011;29(51):9557-62. http://dx.doi.org/10.1016/j. vaccine.2011.09.076 PMid:21964058

31. Prato R, Tafuri S, Fortunato F, Martinelli D. Vaccination in healthcare workers: an Italian perspective. Expert Rev Vaccines. 2010;9(3):277-83. http://dx.doi.org/10.1586/ erv.10.11 PMid:20218856

32. Loulergue P, Moulin F, Vidal-Trecan G, Absi Z, Demontpion $C$, Menager $C$, et al. Knowledge, attitudes and vaccination coverage of healthcare workers regarding occupational vaccinations. Vaccine. 2009;27(31):4240-3 http://dx.doi. org/10.1016/j.vaccine.2009.03.039 PMid:19481314 